\title{
Implementing Aesthetic Education in the Teaching of Chinese Language and Literature
}

\author{
Peng Yan* \\ Zhongyuan University of Technology, Zhengzhou 451191, China \\ *Corresponding author: Peng Yan, 250731857@qq.com
}

\begin{abstract}
Chinese language and literature is an essential subject in colleges as it shoulders an important responsibility in maintaining quality education and imparting elements of humanities to students. The approach of aesthetic education in this discipline is not only the actual demand for quality education in colleges and universities and the all-round development of students in the new era, but also an important way to cultivate the attributes of the discipline itself and students' ability of aesthetic taste. It is the treasure of China's traditional culture and plays an important carrier as well as role in inheriting excellent culture. Using the approach of aesthetic education in the teaching of Chinese language and literature is the focus of educators. Therefore, this article analyzes the strategies of implementing aesthetic education in the teaching of Chinese language and literature and provides a reference basis for the implementation of aesthetic education in this discipline.
\end{abstract}

Keywords: Chinese language and literature; Teaching; Aesthetic education

Publication date: June 2021; Online publication: June 30, 2021

\section{Introduction}

With rapid social development, people's living standards in terms of materials have been greatly improved; however, they have to face the reality that the spiritual world is becoming deserted day by day. Aesthetic education is an effective way to enrich emotions, improve one's personality, and enrich one's inner world. Aesthetic education is one of the important tasks of education in colleges and universities. Chinese language and literature is the main discipline that uses the approach of aesthetic education in its teaching. With aesthetic education, this discipline possesses a unity of humanism and instrumentality along with incomparable advantages with other disciplines. When teachers teach basic courses, they need to accurately grasp the internal laws, closely follow the aesthetic characteristics of Chinese language and literature, organize teaching purposefully, achieve the goal of aesthetic education, and accomplish good teaching results.

\section{Significance of aesthetic education}

\subsection{Improves students' reading ability}

In the process of personal maturity and development, the aesthetic ability of students develops synchronously with their emotions, ideas, and cognitive levels. Aesthetic ability provides students the ability to form scenes depicted by various texts in their minds when reading articles or texts, and at the same time, feel the emotions of the authors so as to deeply understand the text, thus improving their reading ability and cultivating empathy. For example, in regard to lyrical articles, students would be able to understand the author's thoughts during which the text was wrote and accurately grasp the meaning expressed by the author. Other than that, students would have the opportunity to clearly and 
comprehensively grasp the views of argumentative articles as well as put forward their own understanding and views on the theme of these articles. No matter what type of text it is, aesthetic ability helps students to recreate artistic images from various texts, realize the reconstruction imagination of aesthetic images in static texts, deepen their understanding of the views and emotions contained in the texts, and improve their reading ability.

\subsection{Expands students' knowledge}

Aesthetic education is approached with the help of aesthetic activities, arousing students' aesthetic experience and stimulating emotional aesthetic pleasure. Through these activities, students would gradually become interested in articles of a certain type or a certain view, thus transforming their reading behaviors into independent searches for articles of similar type. Taking scenery descriptions as an example, students may feel that the sceneries described by the authors are no longer just simple natural sceneries but endowed with strong subjective colors by the authors. In this way, students develop an interest toward the method of description. This in turn would lead students to search for other articles by the same authors or those with similar writing styles. In this process, students would encounter various reading texts and eventually, broaden their knowledge and reading scope.

\subsection{Adjusts students' mentality}

With the rapid development of the society, many incorrect ideas are gradually emerging, and many college students are affected by utilitarianism and hedonism. College students are in the mature stage both physically and mentally. Self-consciousness and emotions are gradually formed but they are limited by physical and mental conditions. The external expression of their emotions is usually impulsive, blind, changeable, and so on. In this environment, aesthetic education can restore the essence of education, help students eliminate the influence of incorrect ideas, assist in adjusting their self-mentality, transform their instinctive activities in life, as well as lead them to a healthy and beautiful aesthetic environment. Aesthetic education depends on the object that conforms to the aesthetic law. This meaningful formal object can truly awaken students' aesthetic perception, touch their hearts, and improve the cultivation of rational thinking among students so as to make them better face the difficulties and adverse environment, adjust their mentality, and lead a peaceful life.

\section{Strategies of implementing aesthetic education in the teaching of Chinese language and literature}

\subsection{Learning Chinese language and literature and excavating materials for aesthetic education}

With the continuous development and popularization of educational modernization, most teachers focus on innovating teaching methods and means. Whether multimedia technology is used in the classroom or whether a variety of modern teaching means are applied has become the focus of many teachers. They focus on the problem of "How to teach?" but neglect the core problem of "What to teach?". Therefore, in order to better carry out aesthetic education, the most important thing is to solve the fundamental problem of Chinese language and literature teaching. Teachers should shift the focus to literature teaching materials and deeply excavate relevant materials from the vast teaching materials. First of all, in the understanding of the discipline, Chinese language and literature contains innumerable classical culture and traditional culture. The characters and emotional meanings in the texts have certain material functions. Teachers should use these articles wisely to guide students in understanding the essence, characteristics, and purpose of the discipline as well as handle the teaching activities of the discipline appropriately. Secondly, in terms of teaching content, each article has its own rules and methods, which are different and relatively independent from each other. Teachers should guide students to accurately and comprehensively appreciate 
the content of each article, such as the creative art techniques used in the text, the sections mirroring the author's personalized language description or shaping the characters' image with the help of character language and action, as well as the words which are highly expressive. In addition, teachers should also guide their students to split and reconstruct the logical structure of each article and avoid sticking to the standard answer, which would stifle the students' aesthetic enthusiasm. Teachers should not only be good at simplification, but also make rational use of refined words and sentences. When necessary, they can analyze each article from the perspective of "biting words" in addition to the words and structures which the author have used to convey his or her emotions. This would help realize students' aesthetic ability and allow them to appreciate the formal beauty, emotional beauty, and structural beauty of each article. In terms of text art, literature is an important art form, and the article is an important carrier of the art form. The ingenious use, combination, arrangement, logical structure, etc. in each article represent the emotions and thoughts of the author. In teaching, students should be guided to appreciate the art of each text through various forms and experience the beauty brought by art in order to enhance students' artistic appreciation of the text.

\subsection{Enhancing the charm of the subject and stimulating students' enthusiasm in participation}

The learning behavior of students is based on their existing cognitive behaviors and emotional characteristics. Teachers can effectively stimulate students' enthusiasm in participation and improve their learning efficiency only by enhancing the charm of the subject, strengthening the connection with their existing cognitive behaviors, and creating a teaching situation that is acceptable to them in consideration of their interests. There are a few ways to achieve this. One of it is to select materials based on the principle of students' daily life. Teaching materials are the formulated content of students' teaching, which cannot be changed at will during teaching. However, teachers can use a variety of forms to transform the contents of the teaching materials into more interesting situations, add various information to the contents to expand students' knowledge, and mobilize their emotional experience as well as thinking activity. In the context of the rapid development of the internet, teachers can use various network resources to process and reproduce the contents which students are interested in, familiar with, and close to life so as to create a more flexible teaching form that meets students' preferences. The second is to create visible and tangible forms of interaction. Many theories found in Chinese language and literature are connected with practical activities. Teachers should take advantage of this to strengthen the interaction with their students, implement aesthetic education activities in consideration of students' actual life, as well as emphasize individual participation based on students' self-expression and association. It also gives play to students' imagination and creativity as well as improves their literary aesthetic ability.

\subsection{Respecting students' personality and innovating the mode of aesthetic education}

College students are at the stage where they are gradually maturing and developing rational thinking. Their understanding of literary works are also in the direction of rational thinking, and their exploration of things is full of unique and personalized understanding. Teachers should pay attention to students' personalized reading and their development, innovate the aesthetic education mode, as well as improve students' speculative ability, critical ability, and aesthetic ability toward literature. First, teachers should improve their professional level. A large part of students' personal development is related to the guidance and inspiration by teachers. The professional level of teachers plays an important role in students' aesthetic interest and evaluation interest. The second is to broaden students' knowledge. The width of knowledge largely determines the aesthetic ability and appreciation ability. Therefore, teachers should broaden students' knowledge through various forms, such as literary evaluation activities and related keynote speech activities, 
in order to link classroom activities with real life practice. Third, teachers should reasonably design the curriculum. They should not only strengthen the practice of aesthetic education activities, but also enrich the curriculum content, combine students' aesthetic activities with the cultivation of other Chinese abilities, improve the flexibility of training methods, as well as provide opportunities for students to reflect the significance of aesthetic education from teaching and meet their own aesthetic needs. Fourth, teachers should strengthen their innovation of the forms of teaching. Each literary work expresses the author's thoughts and emotions. With different readers and different appreciation angles, there will be different understandings and conclusions. Therefore, the guidance provided by teachers in this aspect is very important. Teachers should appropriately reduce the memory link of knowledge points and add a large number of aesthetic contents to create a reasonable and effective aesthetic experience in order to help students establish correct aesthetic concepts. On the one hand, teachers should select literary works with educational value and those that are in line with the development of students' aesthetic ideas. On the other hand, teachers should analyze the essential thoughts in the literary works, guide students to discuss and understand the beauty of these works, express ideas, and exchange opinions with one another, strengthen the understanding of works through discussions, as well as stimulate research interest.

\section{Conclusion}

To sum up, aesthetic education plays an extremely important role in the teaching of Chinese language and literature. Its cultivation must be based on a correct understanding of "beauty" while excavating the materials of aesthetic education from various teaching materials and innovating teaching forms in relation to aesthetic education. Aesthetic education in Chinese language and literature is not a teaching method, but a teaching thought and realm. It has become a part of cultural construction, which can imperceptibly improve students' language literacy and ability, thus providing an assurance for their all-round development.

\section{Disclosure statement}

The author declares that there is no conflict of interest.

\section{References}

[1] Du Y, Xu F, 2020, Measurement and Implementation: The Focus of Improving Normal Students' Aesthetic Ability - Taking the Major of Chinese Language and Literature of Huaiyin Normal University as an Example. Journal of Huaiyin Normal University (Natural Science Edition), 19(04): 368-369.

[2] Wang J, 2020, On the Effective Application of Aesthetic Education in Chinese Language and Literature Teaching in Colleges and Universities. Journal of Hubei Open Vocational College, 33(04): 151-153.

[3] Li M, 2019, Effective Development of Aesthetic Education in Chinese Language and Literature Teaching in Colleges and Universities. Journal of Kaifeng Institute of Education, 39(09): 154-155.

[4] Fan D, 2017, Implementation of Aesthetic Education in Chinese Language and Literature Teaching [A] National Teachers' Scientific Research Fund Management Office. Scientific Research Achievements of National Teachers' Scientific Research Special Fund (XII). National Teachers' Scientific Research Fund Management Office, 2

[5] Wang X, 2016, Analysis on the Effective Application of Aesthetic Education in Chinese Language and Literature Teaching in Higher Vocational Colleges. Science, Technology and Economy Guide, (33): 185. 